\title{
Understanding the treatment of attention deficit hyperactivity disorder in newly diagnosed adult patients in general practice: a UK database study
}

This article was published in the following Dove Press journal:

Pragmatic and Observational Research

23 January 2015

Number of times this article has been viewed

\author{
Christopher Bushe' \\ Bernard Wilson ${ }^{2}$ \\ Foula Televantou' \\ Mark Belger' \\ Louise Watson ${ }^{3}$ \\ 'Lilly UK, Erl Wood Manor, \\ Windlesham, Surrey, ${ }^{2}$ Lilly UK, Lilly \\ House, Basingstoke, Hampshire, \\ ${ }^{3}$ EpiPharmaCo Ltd, Buxton, \\ Derbyshire, UK
}

Background: Adult attention deficit hyperactivity disorder (ADHD) has been largely ignored in psychiatric and general practice guidance until recently. Adult ADHD has a high social and medical burden, but health care is not well described in the UK. The main study objective was to evaluate a primary care adult ADHD population in terms of prescribing and health care contact rates.

Methods: This was a retrospective observational study using data from the Clinical Practice Research Database from January 1, 2002 to July 31, 2011. Adult patients with an incident ADHD diagnosis or ADHD medication were identified as having been free of ADHD medication or diagnoses in the previous 2 years. Patients were followed for 12-24 months after diagnosis.

Results: Of the 663 patients with ADHD in the cohort, 54.1\% were prescribed ADHD medication during the observation period. During the first 6 months, $34.2 \%$ of patients initiated methylphenidates and $14.0 \%$ atomoxetine. In total, $36.3 \%$ patients were referred to secondary care psychiatry during observation, with the remaining population (63.7\%) never having a referral. Most of the referrals were before diagnosis in primary care. At the end of the observation period, $16.2 \%$ of patients were on antipsychotics, $17.3 \%$ hypnotics, and $34.8 \%$ antidepressants or anxiolytics; however, some patients appeared to be prescribed antipsychotic or antidepressant medications even if they did not have an observable diagnosis in their records. Health care contact rates (general practitioner or hospital) increased by $39.2 \%$ post-diagnosis (incidence rate ratio: $1.39 ; 95 \%$ confidence interval: $1.32,1.47$ ), which may be related to the need for medication monitoring and titration.

Conclusion: This study has shown in primary care that there is relatively low use of ADHD medication, low referrals into secondary care, high rates of usage of psychiatric non-ADHD medications for different indications, and an increasing burden in terms of health care contacts in adult ADHD patients post-diagnosis.

Keywords: adult ADHD, prescribing, health care, health outcomes, epidemiology, CPRD

\section{Background}

There is an increasing recognition that attention deficit hyperactivity disorder (ADHD) frequently continues into adulthood with a plethora of clinical concerns. The European Network for Adult ADHD has stated that adult ADHD is underdiagnosed and, consequently, undertreated with pharmacological and non-pharmacological treatments, leading to a higher cost of illness. ${ }^{1}$ Only recently in 2013, the first licensed treatment for initiation in adults with ADHD (atomoxetine) became available across Europe.

In a large multinational survey across ten countries, which included 11,442 individuals aged 18-44 years, the prevalence of ADHD was estimated to be $3.4 \%$, and the data indicate that the rate of ADHD is higher in high-income countries compared
Correspondence: Christopher Bushe Lilly UK, Erl Wood Manor, Sunninghill Road, Windlesham, Surrey, GU20 6PH, UK

Email bushe_chris@lilly.com
Pragmatic and Observational Research 2015:6 I-12 (c) (i) (2) 2015 Bushe et al. This work is published by Dove Medical Press Limited, and licensed under Creative Commons Attribution - Non Commercial (unported, v3.0) BY LC License. The full terms of the License are available at http://creativecommons.org/licenses/by-nd/3.0/. Non-commercial uses of the work are permitted without any further how to request permission may be found at: http://www.dovepress.com/permissions.php 
to low-income countries ( $4.2 \%$ versus $1.9 \%$, respectively). ${ }^{2}$ A proportion of patients who currently attend secondary care psychiatric clinical practice may have ADHD as a solitary or comorbid illness that is undiagnosed. A UK sample indicated that approximately $20 \%$ of the UK adult psychiatric population who attend outpatient clinics may have ADHD either in addition to or instead of their original diagnosis. ${ }^{3}$ The majority of these patients are currently diagnosed as having depressive or anxiety disorders despite symptoms that may be detectable by screening, and until recently, adult ADHD has been neglected as a treatable condition in the adult segment, ${ }^{4,5}$ despite National Institute of Clinical Excellence (NICE) 2008 (Guidance CG72) ${ }^{6}$ making clear statements regarding treatment and diagnosis. The Diagnostic and Statistical Manual of Mental Disorders, 4th Edition, Text Revision (DSM-IV-TR) ${ }^{7}$ did not specifically provide any diagnostic guidance for adult ADHD, with definitions essentially only relating to diagnosis in childhood. In 2013, the Diagnostic and Statistical Manual of Mental Disorders, 5th Edition (DSM-5) acknowledged specific facets of adult ADHD, which may differ from childhood diagnoses. ${ }^{8}$

Adult patients with ADHD (whether diagnosed in childhood or newly diagnosed in adulthood) have been previously shown to have high rates of medical and social burden. For example, the Rochester birth cohort study reported on outcomes in childhood ADHD patients diagnosed at a mean age of 10 years and followed up at a mean age of 27 years. ${ }^{9}$ The study reported that suicide rates were increased approximately fivefold, and only one third of patients were free from a DSM diagnosis at last follow-up. When compared to the non-ADHD population, patients with the disorder have higher rates of comorbid psychiatric disease, particularly anxiety and depression, as well as higher rates of alcohol and drug abuse, related psychiatric medication use, accidents requiring use of the accident and emergency department, and primary and secondary care attendance..$^{2,4,10-12}$ Data from a cohort of 25,000 patients with ADHD aged older than 15 years from Sweden who were followed for 4 years indicate that ADHD is also associated with an increased risk of criminal behavior but that those patients treated appropriately for ADHD had reductions in criminality of $30 \%-40 \%$ compared to nontreated patients. ${ }^{13}$

For adults, ADHD rarely presents without additional comorbid illness, and this adds to the complexity of diagnosis and treatment. Because of the similarity of presenting symptoms of ADHD to many other psychiatric conditions and their high prevalence among patients with mood, anxiety, substance use, and impulse-control disorders, ${ }^{14,15}$ both psychiatrists and general practitioners (GPs) may find it challenging to identify the various diagnoses. ${ }^{1}$ The British Association of Psychopharmacology produced guidelines for physicians caring for adolescents with ADHD as they reached adulthood and for newly diagnosed adults. ${ }^{16}$ They clearly describe the complexity of the diagnosis that should be performed in the psychiatric secondary care setting, with initial screening and referral most likely performed by the GP. ${ }^{16}$

Little published data are available regarding the medical burden and management of adults with ADHD in the UK. This study was designed to provide this data by evaluating drug prescription, psychiatric referrals, and rates of attendance to health care professionals during the periods before and after the diagnosis of ADHD in a primary care setting.

\section{Methods}

The study was a retrospective database study using the Clinical Practice Research Database (CPRD), evaluating a cohort of adult ADHD patients aged 20 years or older. Patients had been registered for the 2 years before their diagnosis of adult ADHD to ensure that patients could be considered as incident adult ADHD cases, and the study compared variables between the 2 -year pre-diagnosis period and the 2-year post-diagnosis period between January 1, 2002 and July 31, 2011. The CPRD, which is the English National Health Service (NHS) observational data and interventional research service, is jointly funded by the NHS, National Institute for Health Research, and the Medicines and Healthcare products Regulatory Agency. As of September 2013, there were 13.1 million patients with acceptable (research quality) data, of which 5.4 million were active (still registered with a contributing GP practice). In the UK, all patients use a gateway primary care system, and all patient diagnoses are available in their primary care record, regardless of whether the GP is the primary caregiver. The CPRD (formally General Practice Research Database [GPRD]) primary care-derived population has been evaluated as being representative of the general UK population. ${ }^{17}$ As adult ADHD is likely to be underdiagnosed in the UK, the CPRD offered a large database (with more than six million lives recorded) from which to capture those patients with a formal ADHD diagnosis (made either by the GP or in secondary care) or who were treated with ADHD-indicated medications. Diagnoses are identified with Read codes (a coded thesaurus of clinical terms used by the NHS) - applied per visit to define the reason for the visit - the standard clinical terminology system used in general practice in the UK. 
Ethical permission was granted by the CPRD Independent Scientific Advisory Committee (\#13_002R).

\section{Study objectives}

The study's specific objectives were to do the following:

1. Identify an incident-diagnosed adult cohort of ADHD patients (those free from any diagnosis or treatments for ADHD for 2 years before the first visible diagnosis/ ADHD medication recorded in the database)

2. Follow the cohort for 2 years after the first observable diagnosis

3. a) Observe and quantify prescribing of psychiatric medications (any from the classes of antipsychotic [first, second, and third generation] and antidepressant or anxiolytic medications [tricyclics, tricyclic related, mood stabilizers, serotonin reuptake inhibitors, monamine oxidase inhibitors, serotonin norepinephrine reuptake inhibitors, and anxiolytics outside these groups, eg, buspirone, meprobamate]) and hypnotics (benzodiazepines, other hypnotics, eg, zopiclone, zolpidem, and zaleplon plus promethazine) plus ADHD medications

b) Assess the use of psychiatric diagnoses in adult patients with ADHD who were treated or untreated. Psychiatric diagnoses were any Read codes for anxiety disorders, mood disorders, depressive disorders, alcohol or drug addiction, and psychoses

4. Observe and quantify health care contacts (GP visits, referrals to secondary care, reported attendance at the hospital accident and emergency department) before and after the first ADHD diagnosis

5. Compare rates of the above between the two time periods

Medications indicated for ADHD (at that time for children only) were the following:

- Those that contain the active ingredient methylphenidate: Concerta XL, Equasym, Equasym XL, Medikinet, Medikinet XL, and Ritalin. Methylphenidate is also available as a generic (ie, called methylphenidate).

- Those that contain the active ingredient dexamfetamine.

- Those that contain the active ingredient atomoxetine. Strattera is the only one available at present.

\section{Study criteria Inclusion criteria}

i) All adult patients ( $\geq 18$ years) with a clinical diagnostic code for ADHD and/or medications used to treat ADHD between January 1, 2002 and July 31, 2011 were included in the study. Patients had to be $\geq 18$ years in the pre-index 2-year period, so the youngest a patient could be at the index date was aged 20 years.

It was considered to be medically acceptable to include those patients without a formal diagnosis of ADHD who were treated with the listed medications because those medications are almost always specific to ADHD. Narcolepsy is the only other condition for which these drugs are prescribed, ${ }^{18}$ and these patients are excluded (see "Exclusion criteria"). Any other use would be off-label, which is impossible to identify.

ii) The patients must have had at least one observation in each year of the 2 years before index date (ie, they must have had at least one GP visit or medication of any type at any time in both the 1 year before index date and between the 1 year and 2 years before index date). This was required to ensure that the patient was on the GP list and active and had not migrated or died.

iii) The individual must have had at least one GP visit or medication of any type in the 12 months after the index date. This was to again ensure that patients had not migrated or died.

\section{Exclusion criteria}

i) To ensure that patients were newly diagnosed with ADHD during the 2-year pre-diagnosis period, no diagnostic medical/Read code for ADHD/attention deficit disorder could be present or medication indicated for ADHD.

ii) Patients with a medical/Read code for narcolepsy at any time were excluded.

iii) Patients with $<12$-month follow-up after the index date were also excluded because patients must have had adequate time to see the GP and obtain medications and potential referrals.

It should be noted that it was possible that patients may have been diagnosed and treated for ADHD in childhood and then treatment stopped. A new diagnosis could then have been given in adulthood. However, after 2 years without a consult, treatment, referral, or diagnosis for ADHD, the assumption was made that the patient could be treated as newly incident for the purposes of the analyses.

\section{Study follow-up}

Patient follow-up for prescription and event evaluations continued until the end of the 24-month post-index observation period. Patients who did not have a complete 12-month record in the database after the diagnosis (due to death or migration) were not included in analyses. Patients who died 
or migrated between the 12-month and 24-month post-index date were censored at that point.

\section{Study analyses}

The analyses were performed using SAS version 9.2 software and constituted both population frequencies and proportions for the endpoints outlined, with appropriate binomial tests applied and within-person rate comparisons (incidence rate ratios) done for the 2-year periods before and after the first diagnosis of ADHD (defined as the index date). These comparisons were divided into six monthly epochs (time periods of 24-18 months pre-index, 18-12 months pre-index, 12-6 months pre-index, 6 months to index date, and then similar post-index periods). Patients whose data were missing for a particular epoch (eg, prescribing data) but had data in a later epoch were excluded for that specific epoch. Data are presented in each table as patient numbers and proportions of the total patients present in each epoch.

An adjusted negative binomial model ${ }^{19}$ was developed for health care contact rates (GP visits for any cause plus any secondary care referral to psychiatry or neurology). The model was adjusted for age and sex, prescribing of ADHD medications per patient per epoch, plus the year of each patient's index date.

Part of the analyses was to evaluate i) attendance at the hospital accident and emergency department using notes from the GP records and ii) patient attendance with the GP for mental health states frequently associated with ADHD, such as anxiety and depression. For these two analyses, rates were compared for the pre- and post-index periods as a whole and were not evaluated by epoch. To define the mental health states, specific Read codes were identified by examining the 100 most frequently applied diagnostic codes used for visits to the GP by the cohort of patients. It was found that very few specific DSM-IV recognized terms ${ }^{7}$ had been coded for these visits, so commonly applied codes were identified, which tended to use less-specific terminology. The following were selected, which related to any of the psychiatric illnesses: a) seen in psychiatry clinic, b) mental health review, c) seen by a psychiatrist, d) low mood, e) chest pain (often presenting in patients with anxiety codes), f) anxiety states, g) stress at home, and h) anxiousness - symptom. These were combined together into one group "key conditions". The rate of attendance for key conditions was then compared to pre- and post-index date (see Supplmentary material).

\section{Results}

A total of 1,695 individuals were initially identified who had either an ADHD diagnosis or treatment for ADHD. Figure 1 describes the selection process, with 663 patients fulfilling all of the criteria and forming the main cohort.

The patient population $(\mathrm{N}=663)$ contained 601 patients with a diagnostic code for ADHD (with or without medications) and 62 patients who did not have a diagnostic code for the condition but were treated with ADHD medications (Table 1). Of the total 663 patients in the cohort, only 359 $(54.1 \%)$ were treated for the condition with medication. Of those with formal diagnosis, only $49.4 \%$ were treated. The majority ( $n=436 ; 65.8 \%$ ) of patients were men, and median age was 31 years.

Of the total cohort $(\mathrm{N}=663), 227(34.2 \%)$ initiated treatment in the first 6 months post-diagnosis on methylphenidates (Table 2). Fourteen percent initiated treatment on atomoxetine, and this had reduced by half after 2 years, whereas the proportion receiving methylphenidate remained relatively consistent. Dexamphetamine accounted for $<2 \%$ of treated patients at any time post-diagnosis. The prescribing of ADHD medications over time was similar for patients with and without a diagnosis of an additional psychiatric condition.

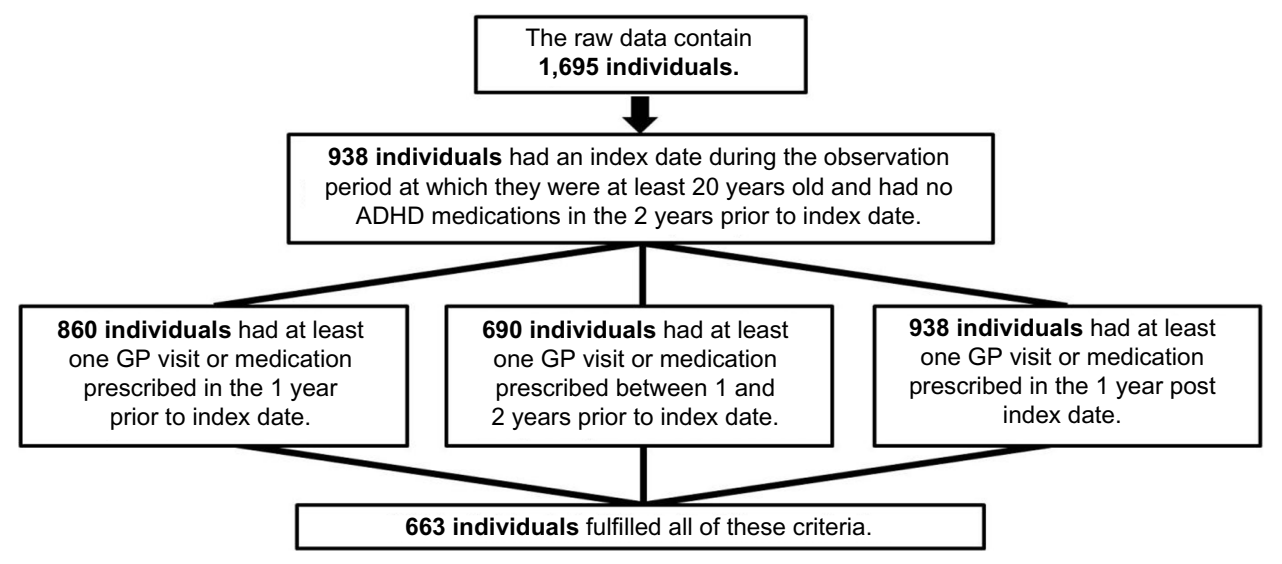

Figure I Patient population.

Abbreviations: ADHD, attention deficit hyperactivity disorder; GP, general practitioner. 
Table I Description of the patient population

\begin{tabular}{|c|c|c|c|}
\hline $\begin{array}{l}\text { Patient } \\
\text { characteristics }\end{array}$ & $\begin{array}{l}\text { Included } \\
\text { patients with } \\
\text { Dx code } \\
(\mathbf{N}=601)\end{array}$ & $\begin{array}{l}\text { Included } \\
\text { patients } \\
\text { with meds } \\
\text { only }(\mathrm{N}=62)\end{array}$ & $\begin{array}{l}\text { All } \\
\text { analysis } \\
\text { patients } \\
(\mathrm{N}=663)\end{array}$ \\
\hline \multicolumn{4}{|l|}{$\overline{\text { Age }}$} \\
\hline Mean (SD) & $33.5(13.36)$ & $34.0(15.06)$ & $\begin{array}{l}33.6 \\
(13.52)\end{array}$ \\
\hline Median (range) & $31.0(20-98)$ & $28.0(20-82)$ & $\begin{array}{l}31.0 \\
(20-98)\end{array}$ \\
\hline Male, n (\%) & $389(64.7)$ & $47(75.8)$ & $\begin{array}{l}436 \\
(65.8)\end{array}$ \\
\hline $\begin{array}{l}\text { Mean (SD) observation } \\
\text { time (days) }\end{array}$ & $\begin{array}{l}I, 183.6 \\
(267.1)\end{array}$ & $\begin{array}{l}1,198.0 \\
(255.5)\end{array}$ & $\begin{array}{l}\mathrm{I}, 184.9 \\
(265.9)\end{array}$ \\
\hline $\begin{array}{l}\text { Patients with at least } \\
\text { one ADHD medication } \\
\text { prescription, } \mathrm{n}(\%)\end{array}$ & $297(49.4)$ & $62(100.0)$ & $\begin{array}{l}359 \\
(54.1)\end{array}$ \\
\hline $\begin{array}{l}\text { Methylphenidates }{ }^{\mathrm{a}} \text {, } \\
\mathrm{n}(\%)\end{array}$ & $257(86.5)$ & $28(45.2)$ & $\begin{array}{l}285 \\
(79.4)\end{array}$ \\
\hline Dexamfetamine ${ }^{\mathrm{a}}, \mathrm{n}(\%)$ & $21(7.1)$ & $0(0.0)$ & $21(5.8)$ \\
\hline Atomoxetine $^{\mathrm{a}}, \mathrm{n}(\%)$ & $77(25.9)$ & $46(74.2)$ & $\begin{array}{l}123 \\
(34.3)\end{array}$ \\
\hline
\end{tabular}

Note: apatients could have more than one type of ADHD medication prescribed during observation and may contribute to more than one group over time. Abbreviations: $A D H D$, attention deficient hyperactivity disorder; $D x$, diagnosis; meds, medications; SD, standard deviation.

All patients were stratified according to whether they were prescribed ADHD medications or not, and the use of psychiatric medications was explored in these two groups per epoch (Table 3 and Figure 2). The prescribing of antipsychotics, hypnotics, antidepressants, and anxiolytics increased over time in both groups (Table 3 ). At the end of the observation period, $16.2 \%$ of patients were being prescribed antipsychotics, $17.3 \%$ hypnotics, and $34.8 \%$ antidepressants or anxiolytics. Recorded diagnosis of psychiatric conditions tended to increase over time; however, a number of patients appear to have been prescribed antipsychotic or antidepressant medications without an observable diagnosis in their records.

Health care contact rates increased significantly postdiagnosis, with an incidence rate ratio of 1.33 (95\% confidence interval: $1.24,1.43$ ), or a $33 \%$ increase (Table 4 ). When subgroups of psychiatric drug users were tested in the model, all showed a significant increase in attendance post-diagnosis, with antipsychotic users having the greatest increase $(39.3 \%)$ of the subgroups but not significantly more than hypnotic or antidepressant users.

Table 5 and Figure 3 illustrate secondary care referrals and show the proportions referred before and after the index date. In total, 241 (36.3\%) patients were referred one or more times to the psychiatric clinic at anytime during observation, with the remaining population (63.7\%) never having a referral. Most of the referrals (62.7\%) were before diagnosis, with $37.3 \%$ of referrals after diagnosis, indicating that the majority of patients had no referral into outpatient psychiatry at this time despite being given a diagnosis of ADHD or taking ADHD medication.

Large numbers of patients in the cohort $(53.2 \%$ of 663 patients after ADHD diagnosis) attended the GP with visits coded in relation to key psychiatric terms or were recorded as having attended the psychiatric clinic (29.7\%). More patients attended psychiatric clinics postdiagnosis $(29.7 \%)$ than pre-diagnosis $(17.8 \%)(P<0.0001)$ (Table 6). The hospital accident and emergency department had rates of attendance for all disorders, which increased

Table 2 Patients with ADHD medications by type, per 6-month epoch, stratified by any other psychiatric diagnoses

\begin{tabular}{|c|c|c|c|c|c|}
\hline $\begin{array}{l}\text { Patients with } \\
\text { ADHD medication }\end{array}$ & $\begin{array}{l}24 \text { months } \\
\text { pre-index } \\
(\mathrm{N}=663)\end{array}$ & $\begin{array}{l}\text { Index to } 6 \text { months } \\
\text { post-index } \\
(\mathrm{N}=663)\end{array}$ & $\begin{array}{l}6-12 \text { months } \\
\text { post-index } \\
(\mathrm{N}=585)\end{array}$ & $\begin{array}{l}\text { I2-I8 months } \\
\text { post-index } \\
(\mathrm{N}=533)\end{array}$ & $\begin{array}{l}\text { I8-24 months } \\
\text { post-index } \\
(\mathrm{N}=468)\end{array}$ \\
\hline \multicolumn{6}{|l|}{ All patients } \\
\hline Methylphenidates, n (\%) & $0(0.0)$ & $227(34.2)$ & $184(31.5)$ & $164(30.8)$ & $142(30.3)$ \\
\hline Dexamfetamine, n (\%) & $0(0.0)$ & $8(1.2)$ & $10(1.7)$ & $10(1.9)$ & $9(1.9)$ \\
\hline Atomoxetine, n (\%) & $0(0.0)$ & $93(14.0)$ & $53(9.1)$ & $45(8.4)$ & $34(7.3)$ \\
\hline \multicolumn{6}{|c|}{ Patients without any psychiatric $D x$ at any time } \\
\hline $\mathrm{N}$ & 415 & 415 & 359 & 328 & 284 \\
\hline Methylphenidates, n (\%) & $0(0.0)$ & |4| (34.0) & $112(31.2)$ & $99(30.2)$ & $80(28.2)$ \\
\hline Dexamfetamine, n (\%) & $0(0.0)$ & $6(1.4)$ & $4(1.1)$ & $4(1.2)$ & $4(1.4)$ \\
\hline Atomoxetine, n (\%) & $0(0.0)$ & $54(13.0)$ & $34(9.5)$ & $28(8.5)$ & $23(8.1)$ \\
\hline \multicolumn{6}{|c|}{ Patients with any one of the psychiatric Dxs } \\
\hline $\mathrm{N}$ & 248 & 248 & 226 & 205 & 184 \\
\hline Methylphenidates, n (\%) & $0(0.0)$ & $86(34.7)$ & $72(31.9)$ & $65(31.7)$ & $62(33.7)$ \\
\hline Dexamfetamine, n (\%) & $0(0.0)$ & $2(0.8)$ & $6(2.7)$ & $6(2.9)$ & $5(2.7)$ \\
\hline Atomoxetine, n (\%) & $0(0.0)$ & 39 (I5.7) & $19(8.4)$ & $17(8.3)$ & II (6.0) \\
\hline
\end{tabular}

Notes: Patients may contribute to more than one cell. The percentages given represent the number of individuals who had each specific medication out of the total number of patients within the epoch.

Abbreviations: ADHD, attention deficit hyperactivity disorder; Dx, diagnosis; Dxs, diagnoses. 


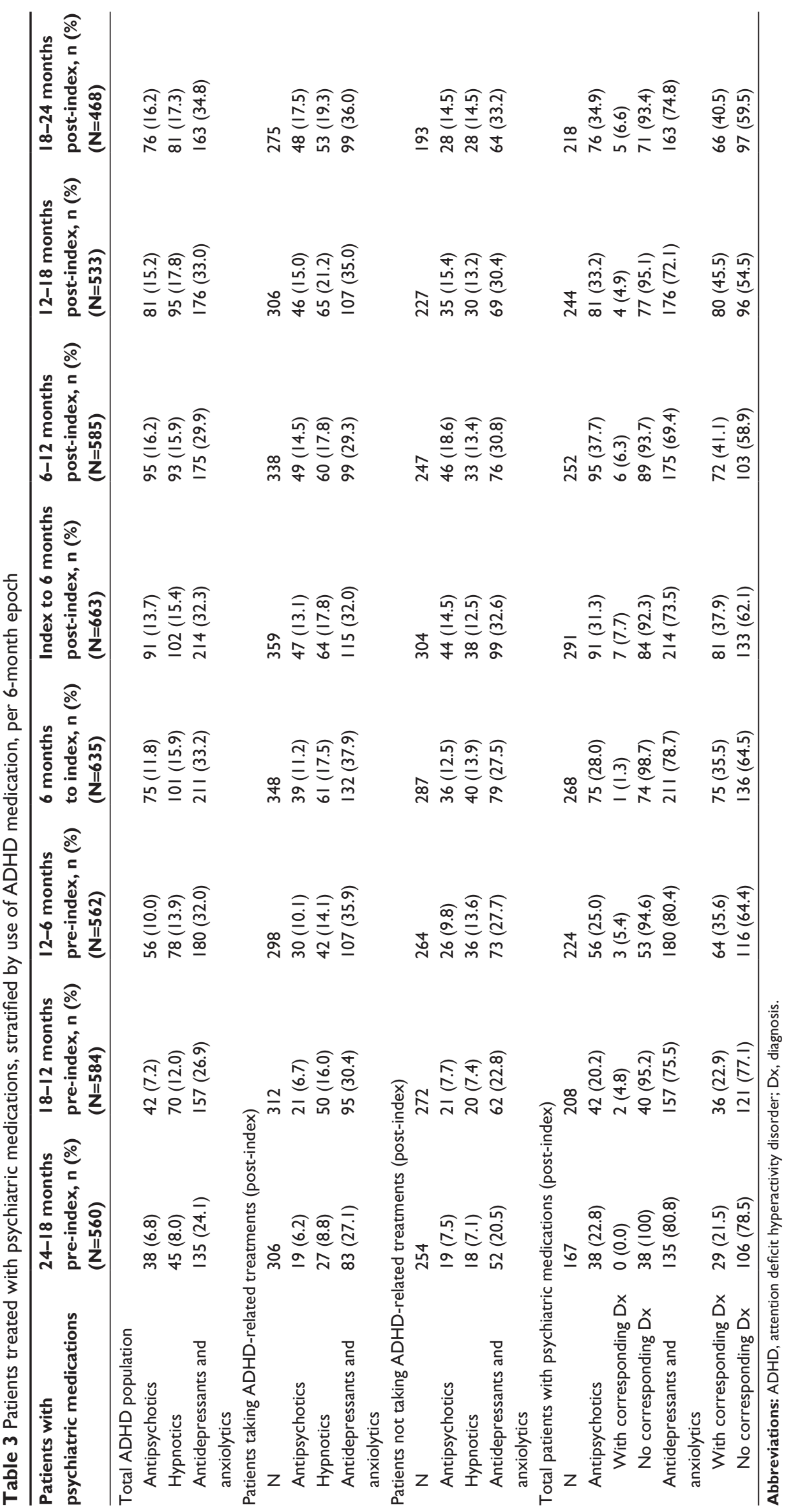




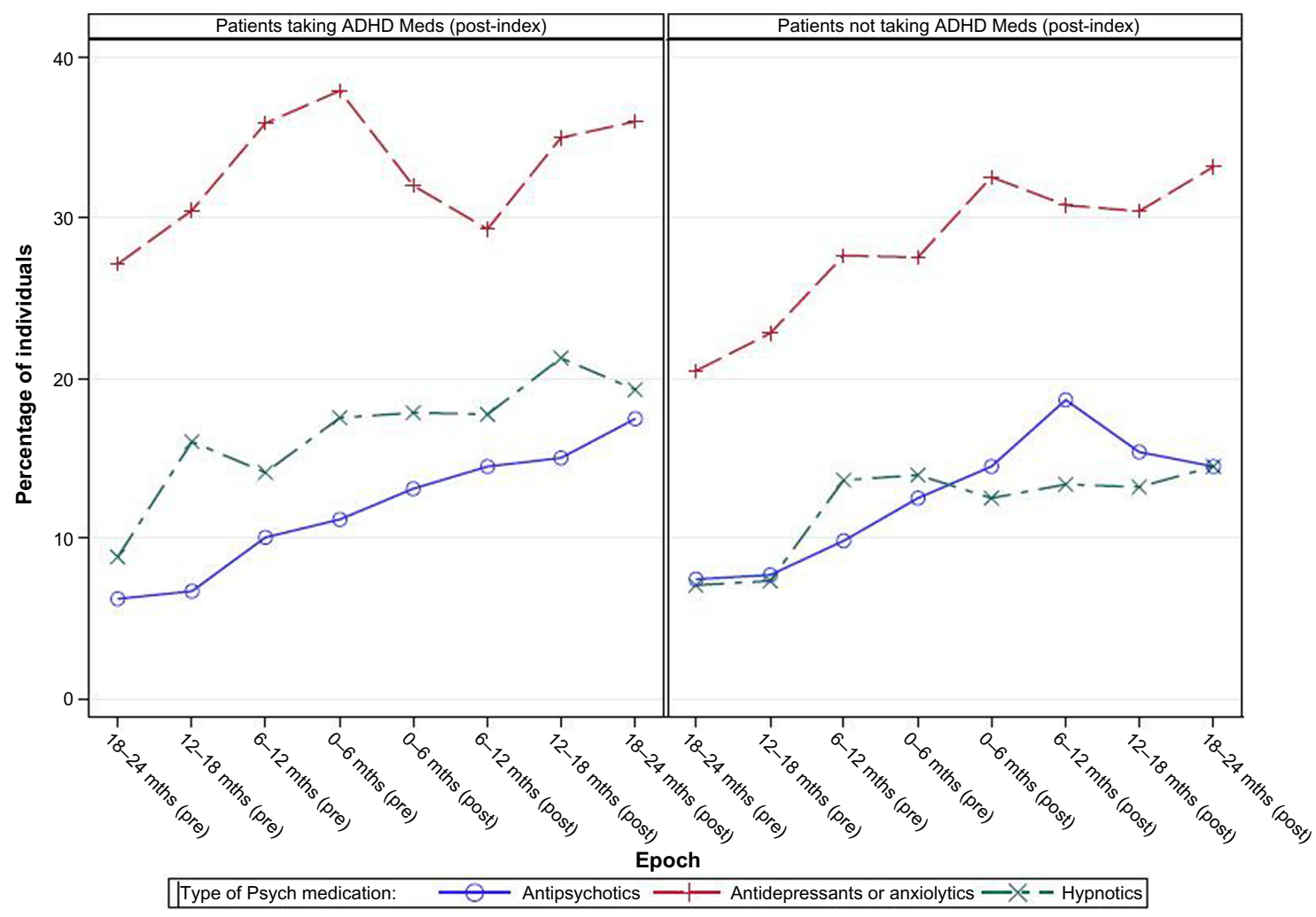

Figure 2 Longitudinal psychiatric medication use in the total population per epoch, stratified by patients prescribed ADHD medications and those who are not. Abbreviations: ADHD, attention deficit hyperactivity disorder; Meds, medications; mths, months; Psych, psychiatric.

significantly after the diagnosis of ADHD from $15.4 \%$ to $19.2 \%(P=0.01)$.

\section{Discussion}

Our study in primary care using the CPRD finds that despite diagnoses of adult ADHD being recorded, only 54\% of patients were receiving ADHD medications and that 63.7\% of patients did not have any referral into secondary care, even though health care contact rates had increased by $39 \%$ after ADHD diagnosis. In contrast, there was relatively high use of non-ADHD medication. At the end of the observation period, $16.2 \%$ of patients were on antipsychotics, $17.3 \%$ hypnotics, and $34.8 \%$ antidepressants or anxiolytics.
This study covers a time period when the initiation of treatment for ADHD in adults was not a licensed indication in the UK for any medication and a period when only a few guidelines or recommendations were available regarding how to treat adult ADHD. During this study period, despite a relative lack of published information available in primary care, our data indicate that ADHD diagnoses were being made in primary care in adults, in agreement with other studies. ${ }^{20}$ The diagnosis codes for ADHD are specific in our study and could not be misconstrued for any other condition, neither by the GP nor during analysis. The primary care data reported over 2003-2008 from The Health Improvement Network UK database (THIN) also report that despite an increase in

Table 4 Health contact (GP all-cause or secondary care referral for ADHD)-adjusted negative binomial rate model

\begin{tabular}{|c|c|c|c|c|c|c|}
\hline Health contact rates ${ }^{a}$ & $\begin{array}{l}\text { Rate } \\
\text { pre-index }\end{array}$ & $\begin{array}{l}\text { Rate } \\
\text { post-index }\end{array}$ & $\begin{array}{l}\text { IRR post-versus } \\
\text { pre-index }\end{array}$ & $\begin{array}{l}95 \% \mathrm{Cl} \\
\text { lower }\end{array}$ & $\begin{array}{l}95 \% \mathrm{Cl} \\
\text { upper }\end{array}$ & $P$-value \\
\hline Unadjusted rate & 13.01 & 18.12 & 1.39 & 1.32 & 1.47 & $<0.0001$ \\
\hline Adjusted rate & 12.65 & 16.86 & 1.33 & 1.24 & 1.43 & $<0.0001$ \\
\hline Antipsychotic users subgroup & 15.15 & 21.10 & 1.39 & 1.23 & 1.57 & $<0.0001$ \\
\hline Hypnotic users subgroup & 15.29 & 20.89 & 1.37 & 1.22 & 1.53 & $<0.0001$ \\
\hline Antidepressant or anxiolytic users subgroup & 14.82 & 18.53 & 1.25 & 1.15 & 1.36 & $<0.0001$ \\
\hline
\end{tabular}

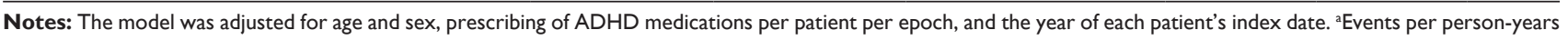
of observation.

Abbreviations: ADHD, attention deficit hyperactivity disorder; $\mathrm{Cl}$, confidence interval; GP, general practitioner; IRR, incidence rate ratio. 
Table 5 Neurology or psychiatry referrals

\begin{tabular}{|c|c|c|c|c|c|c|c|c|}
\hline Referrals & $\begin{array}{l}\text { 24-18 months } \\
\text { pre-index, } \\
\mathrm{N}=560\end{array}$ & $\begin{array}{l}\text { I8-12 months } \\
\text { pre-index, } \\
\mathrm{N}=584\end{array}$ & $\begin{array}{l}\text { I2-6 months } \\
\text { pre-index, } \\
\mathrm{N}=562\end{array}$ & $\begin{array}{l}6 \text { months } \\
\text { to index, } \\
\mathrm{N}=635\end{array}$ & $\begin{array}{l}\text { Index to } \\
6 \text { months } \\
\text { post-index, } \\
N=663\end{array}$ & $\begin{array}{l}\text { 6-12 months } \\
\text { post-index, } \\
\mathrm{N}=585\end{array}$ & $\begin{array}{l}\text { I } 2-18 \text { months } \\
\text { post-index, } \\
\mathrm{N}=533\end{array}$ & $\begin{array}{l}\text { I 8-24 months } \\
\text { post-index, } \\
\mathrm{N}=468\end{array}$ \\
\hline $\begin{array}{l}\text { Routine } \\
\text { neurology, n (\%) }\end{array}$ & $4(0.7)$ & $4(0.7)$ & $7(1.2)$ & $9(1.4)$ & $2(0.3)$ & I (0.2) & I (0.2) & $0(0.0)$ \\
\hline $\begin{array}{l}\text { Routine } \\
\text { psychiatry, n (\%) }\end{array}$ & $22(3.9)$ & $28(4.8)$ & $53(9.4)$ & $92(14.5)$ & $67(10.1)$ & $25(4.3)$ & $22(4 . I)$ & $16(3.4)$ \\
\hline $\begin{array}{l}\text { Urgent } \\
\text { neurology, n (\%) }\end{array}$ & $0(0.0)$ & I $(0.2)$ & $0(0.0)$ & $0(0.0)$ & I (0.2) & $0(0.0)$ & $0(0.0)$ & $0(0.0)$ \\
\hline $\begin{array}{l}\text { Urgent } \\
\text { psychiatry, n (\%) }\end{array}$ & $2(0.4)$ & $2(0.3)$ & $3(0.5)$ & $5(0.8)$ & $3(0.5)$ & $0(0.0)$ & $0(0.0)$ & $0(0.0)$ \\
\hline
\end{tabular}

the numbers of adults being treated for ADHD, the numbers are small in comparison to child cohorts. ${ }^{20}$ Further data were reported from CPRD during 1998-2010 showing that although there was an increased rate of adult ADHD from $6.9 / 100,000$ in 1998 to $9.9 / 100,000$ in 2009, these rates of diagnosis remain minimal in comparison to the prevalence rates reported worldwide of around $3.4 \%{ }^{2,21}$ In addition, the mean total health care costs were four times higher in the ADHD cohort than in those without ADHD. ${ }^{21}$

Our study found that only $36.3 \%$ of patients were referred to secondary care at any time during the observation period, and approximately two thirds of referrals were before the diagnosis of ADHD. These figures must be regarded as estimates because there are a number of limitations when analyzing a database of this kind. For example, because we were unable to scan free text within the database and referrals could have been made using free text letters, the number of referrals may have been underestimated. The data show that $29.7 \%$ of patients diagnosed with ADHD were seen in a general practice psychiatric clinic post-diagnosis but that up to $53.2 \%$ actually had a marker for a potential psychiatric intervention when including endpoints such as "mental health review" and hospital accident and emergency department visits. These data may also be confounded by the relative lack of service provision for adult ADHD in many regions of the UK at this time, leading to a pragmatic inability to

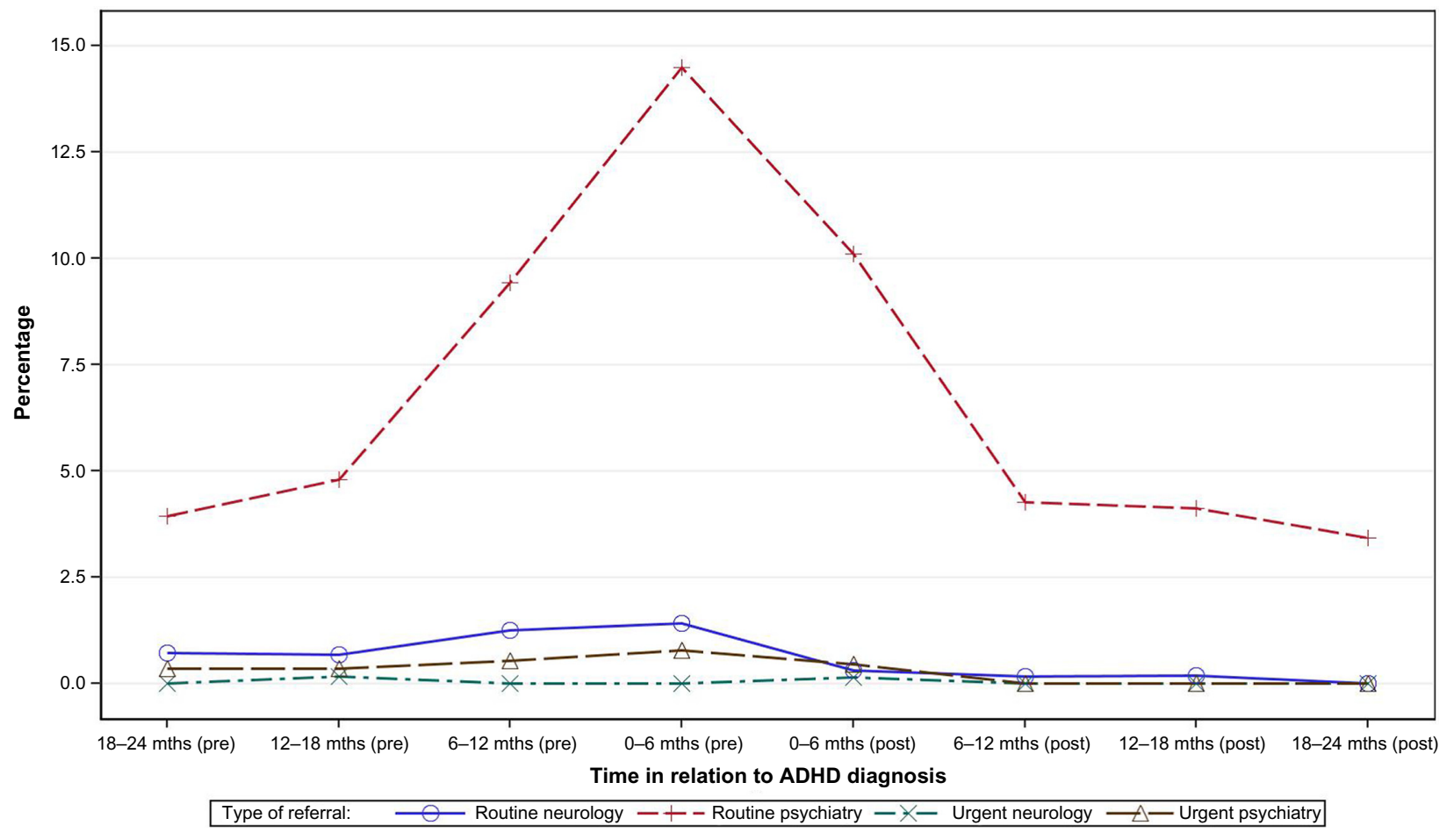

Figure 3 Proportion of the ADHD population referred to secondary care. Abbreviations: ADHD, attention deficit hyperactivity disorder; mths, months. 
Table 6 Attendance for mental health issues and hospital "accident and emergency" attendance

\begin{tabular}{llll}
\hline Comorbidity & \multicolumn{2}{l}{ Frequency, n (\%) } & P-value \\
\cline { 2 - 3 } conditions & $\begin{array}{l}\text { Pre-index } \\
(\mathbf{N}=663)\end{array}$ & $\begin{array}{l}\text { Post-index } \\
\mathbf{( N = 6 6 3 )}\end{array}$ \\
\hline Key conditions & $275(41.5)$ & $353(53.2)$ & $<0.000$ I \\
Seen in psychiatry clinic & II8(I7.8) & $197(29.7)$ & $<0.000$ I \\
Mental health review & $56(8.4)$ & $80(12.1)$ & 0.0018 \\
Seen by psychiatrist & $46(6.9)$ & $65(9.8)$ & 0.0070 \\
Low mood & $40(6.0)$ & $37(5.6)$ & 0.6983 \\
Chest pain & $28(4.2)$ & $33(5.0)$ & 0.3806 \\
Anxiety states & $42(6.3)$ & $28(4.2)$ & 0.0243 \\
Stress at home & $27(4.1)$ & $29(4.4)$ & 0.7474 \\
Anxiousness - symptom & 3 I (4.7) & $32(4.8)$ & 0.9048 \\
Seen in hospital & I02(I5.4) & $127(19.2)$ & 0.010 I \\
accident and emergency & & & \\
\hline
\end{tabular}

refer to secondary care. Nevertheless, it must be of concern that many patients diagnosed with ADHD by GPs may not have received any secondary care confirmation of diagnosis or specialist treatment for managing medications. Guidance requires that if a GP diagnoses or suspects ADHD, the patient should be referred to secondary care. Although it cannot be excluded that ADHD medications are being prescribed to treat another condition aside from ADHD, this is clinically unlikely because of the medication types, classes, and clinical actions and would potentially be of concern. Despite 663 patients in our cohort having ADHD (either with a formal recorded diagnosis or by receiving ADHD medication), only $54.1 \%$ of these patients were treated with ADHD medication.

Our study covers the period from January 2002 to July 2011. Until publication of the first British Association of Psychopharmacology guidelines in $2006^{16}$ and the NICE guidelines (2008 - CG72), ${ }^{6}$ there was little specific management advice for adult ADHD in the UK. In 2008, NICE gave a clear recommendation that, for most patients, pharmacological treatments should be the initial treatment of choice. However, some patients may prefer cognitive behavioral psychotherapy and other psychosocial interventions. Thus, we cannot be sure that such non-pharmacological treatments were not utilized instead of medication; however, it can be assumed that such treatments are not widely available. The absence of this information is a further limitation of our study. However, the prescribing scenario is accurate, and the lack of pharmacological intervention may have been influenced by both a lack of adult licenses for these medications and that all medications, except atomoxetine, are controlled substances, hence making primary care prescribing complex.
Our data support the findings of Fayyad et al, ${ }^{2}$ who found that pharmacological treatment is limited in adult ADHD, and of Kooij et al, ${ }^{1}$ who view that adult ADHD is currently poorly served within European populations. GPs could be concerned about the efficacy of treatments in adults, but various studies have shown that all of the available treatments are highly efficacious if used at appropriate doses. ${ }^{22-25}$ Concerns about the risks of serious cardiovascular events arising from exposure to these drugs could reduce prescribing, but there is no current systematic evidence to support any increased risk. ${ }^{26}$

Patients would appear to be showing the expected high rates of psychiatric comorbidity consistent with previous studies, ${ }^{2,10,11}$ but this was mainly identified by using prescribing information because the diagnostic codes for these conditions were rarely observable in the data. A simple explanation could be that diagnoses were made historically outside the observation period. Sixteen percent of patients were treated with antipsychotics 2 years post-diagnosis. However, a number of these patients had no diagnostic code in their record at any time neither for any type of psychosis or bipolar disorder nor for symptoms recognizable as such. This indicates that GPs could be relying on these medications to treat the ADHD or to manage the symptoms of ADHD that have been mistaken as resulting from an alternative or comorbid psychiatric condition. This is of concern because antipsychotics have no effect in such patients unless comorbid bipolar disease or psychosis is present ${ }^{16}$ and because adverse effects, such as akathisia, may potentially worsen ADHD symptoms. These drugs require high levels of monitoring and have side effects such as weight gain (with subsequent obesity) and hyperprolactinemia. ${ }^{27,28}$ Antidepressants, specifically imipramine and bupropion, are not licensed and only recommended as second-line treatment for ADHD unless comorbid anxiety and depression are present. ${ }^{16}$

GP and secondary care contacts combined increased by $39.2 \%$ post-diagnosis. The increase in GP contacts postdiagnosis is likely to be accounted for by the need to evaluate not only treatment but also medication monitoring. The licenses for all ADHD medications are similar and mandate the need for baseline and 6-month cardiovascular monitoring. The majority will be undertaken in primary care. Monitoring of other drugs, such as antipsychotics, may also contribute to attendance.

Attendance at the accident and emergency department increased significantly post-diagnosis, although it is not clear why this should occur. There have been previous findings that untreated ADHD patients suffer accidents and have higher societal burden generally than those without the condition. ${ }^{12}$ 
Longer term data will be needed to ascertain whether patient burden reduces beyond 2 years post-diagnosis. In larger databases of ADHD cohorts followed for 4 years, ADHD medication treatments have been shown to reduce rates of crime and rates of serious traffic accidents. ${ }^{29}$

Furthermore, there is a wide variety of medical, societal, and other burdens that have the potential for significant improvement. The relatively low rates of ADHD medication prescribing and concomitant usage of other medications are unlikely to be beneficial in the longer term for patients in whom ADHD symptoms are the main reason for impairment. Increasing awareness of ADHD in adults and availability of effective treatments may lead to improved outcomes over subsequent years, and this may be reflected in future studies.

\section{Limitations}

There are significant limitations to using a database such as this, not the least of which is the reliance on appropriate visit coding applied by the GP. While we have endeavored to control for use of stimulants by patients without ADHD by excluding those with narcolepsy, we cannot control for off-label use of drugs related to weight loss, for example. However, we do not believe that such usage is widespread and would have unduly biased the results. Additionally, we cannot evaluate whether prescribing anomalies are due to primary or secondary care instruction. It is also difficult to ascertain whether missing psychiatric diagnoses (despite medication) are due to codes being entered earlier in the database and outside of the observation period. However, over a 4-year period, appropriate diagnostic codes should be used at least once in patients attending for various mental health issues. Dates of diagnosis in such a database are also open to some error in that dates of communications from secondary care may be inadvertently entered as the dates of diagnosis. Data on referral rates and their timings, thus, do appear potentially restricted by limitations of the data-coding system and probable use of free text. However, more than half of patients with ADHD remained without apparent secondary care attendance, and further research is required to determine whether this is true or an anomaly of the data. If it is the real situation, further education in primary care is required for this poorly understood disease that may include use of simple screening tools, such as the Adult ADHD Self-Report Scale screener (a six-question tool). ${ }^{30}$

This study did not evaluate patients diagnosed in adulthood if they did not fit the study criteria of a 2-year free period prior to first observable diagnosis. Nor did the study include patients who transition from childhood to adulthood ADHD. Whether these patients also exhibit the same treatment regimens as this study cohort is not clear, but further research is clearly required to better understand adult ADHD patients. The study also did not undertake individual treatment regimen evaluations to identify switchers or one-time users, which could explain some of the additional prescribing undertaken by GPs, if patients were intolerant or noncompliant with ADHD-indicated medications. However, if this was the case, then it would be imperative to refer such patients to secondary care to better control disease management.

\section{Conclusion}

This study has highlighted areas of concern in the care of patients with adult ADHD in primary care settings in the UK over essentially the previous decade, most notably lack of specific ADHD-related prescribing and potential usage of non-ADHD medications. Implementation of further ADHD education both on illness factors and management may help address our findings and potentially improve patient outcomes.

\section{Acknowledgments}

We would like to thank Dr Aiden Flynn and Dr Lisa McKrink for the programming and analyses of the data. This study was funded by Lilly UK.

\section{Author contributions}

$\mathrm{C}$ Bushe and B Wilson provided the design concept and C Bushe provided medical input. C Bushe, B Wilson, $\mathrm{F}$ Televantou, and $\mathrm{M}$ Belger assisted in protocol development, review of data, and drafting of the manuscript. L Watson provided consultancy service to the company, designed the protocol and analyses, reviewed data, and wrote the manuscript with $\mathrm{C}$ Bushe. The paper was written by the named authors.

\section{Disclosure}

C Bushe and M Belger are full-time employees of Lilly UK. B Wilson and F Televantou were full-time employees of Lilly UK at the time of writing. $L$ Watson has received funding from Lilly UK to undertake these analyses and acts as an epidemiology consultant to various pharmaceutical companies. The authors report no other conflicts of interest in this work.

\section{References}

1. Kooij SJ, Bejerot S, Blackwell A, et al. European consensus statement on diagnosis and treatment of adult ADHD: the European Network Adult ADHD. BMC Psychiatry. 2010;10:67. 
2. Fayyad J, De Graaf R, Kessler R, et al. Cross-national prevalence and correlates of adult attention-deficit hyperactivity disorder. $\mathrm{Br} J$ Psychiatry. 2007;190:402-409.

3. Syed H, Masaud TM, Nkire N, Iro C, Garland MR. Brief report estimating the prevalence of adult ADHD in the psychiatric clinic: a cross-sectional study using the adult ADHD self-report scale (ASRS). Ir J Psychol Med. 2010;58:9-11.

4. Kessler RC, Adler L, Barkley R, et al. The prevalence and correlates of adult ADHD in the United States: results from the National Comorbidity Survey Replication. NIH Public Access. Am J Psychiatry. 2006;163: 716-723.

5. Murphy K. Adults with attention deficit hyperactivity disorder: assessment and treatment considerations. Semin Speech Lang. 1996;17: 245-253.

6. Nice Guidance; 2008. Available from: http://guidance.nice.org.uk/ CG72/NICEGuidance/pdf/English.

7. American Psychiatric Association. Diagnostic and Statistical Manual of Mental Disorders. 4th ed. Washington, DC: American Psychiatric Association; 2000.

8. American Psychiatric Association. Diagnostic and Statistical Manual of Mental Disorders. 5th ed. Washington, DC: American Psychiatric Association; 2013.

9. Barbaresi WJ, Colligan RC, Weaver AL, Voigt RG, Killian JM, Katusic SK. Mortality, ADHD, and psychosocial adversity in adults with childhood ADHD: a prospective study. Pediatrics. 2013;131: 637-644.

10. McCarthy S, Wilton L, Murray M, Hodgkins P, Asherson P, Wong IC. Management of adult attention deficit hyperactivity disorder in UK primary care: a survey of general practitioners. Health Qual Life Outcomes. 2013;11:22.

11. Gjervan B, Torgersen T, Nordahl HM, Rasmussen K. Functional impairment and occupational outcome in adults with ADHD. J Atten Disord. 2012;16:544-552.

12. Asherson P, Akehurst R, Kooij JJ, et al. Under diagnosis of adult ADHD: cultural influences and societal burden. J Atten Disord. 2012; 16(Suppl 5):S20-S38.

13. Lichtenstein P, Halldner L, Zetterqvist J, et al. Medication for attention deficit-hyperactivity disorder and criminality. NEngl J Med. 2012;367: 2006-2014.

14. Barkley RA, Brown TE. Unrecognized attention-deficit/hyperactivity disorder in adults presenting with other psychiatric disorders. CNS Spectr. 2008;13:977-984.

15. Das D, Cherbuin N, Butterworth P, Anstey KJ, Easteal S. A populationbased study of attention deficit/hyperactivity disorder symptoms and associated impairment in middle-aged adults. PLoS One. 2012;7: e31500.

16. Bolea-Alamañac B, Nutt DJ, Adamou M, et al; British Association for Psychopharmacology. Evidence-based guidelines for the pharmacological management of attention deficit hyperactivity disorder: update on recommendations from the British Association for Psychopharmacology. J Psychopharmacol. 2014;28:179-203.
17. Jick SS, Kaye JA, Vasilakis-Scaramozza C, et al. Validity of the general practice research database. Pharmacotherapy. 2003;23:686-689.

18. British National Formulary. 2014. Available from: http://www.bnf.org/ bnf/index.htm.

19. Laird NM, Ware JH. Random-effects models for longitudinal data. Biometrics. 1982;38:963-974.

20. McCarthy S, Wilton L, Murray ML, Hodgkins P, Asherson P, Wong IC. The epidemiology of pharmacologically treated attention deficit hyperactivity disorder (ADHD) in children, adolescents and adults in UK primary care. BMC Pediatr. 2012;12:78.

21. Holden SE, Jenkins-Jones S, Poole CD, Morgan CL, Coghill D, Currie CJ. The prevalence and incidence, resource use and financial costs of treating people with attention deficit/hyperactivity disorder (ADHD) in the United Kingdom (1998 to 2010). Child Adolesc Psychiatr Ment Health. 2013;7:34.

22. Fredriksen M, Halmøy A, Faraone SV, Haavik J. Long-term efficacy and safety of treatment with stimulants and atomoxetine in adult ADHD: a review of controlled and naturalistic studies. Eur Neuropsychopharmacol. 2013;23:508-527.

23. Durell TM, Adler LA, Williams DW, et al. Atomoxetine treatment of attention-deficit/hyperactivity disorder in young adults with assessment of functional outcomes: a randomized, double-blind, placebo-controlled clinical trial. J Clin Psychopharmacol. 2013;33:45-54.

24. Adler LA, Spencer T, Brown TE, et al. Once-daily atomoxetine for adult attention-deficit/hyperactivity disorder: a 6-month, double-blind trial. J Clin Psychopharmacol. 2009;29:44-50.

25. Sobanski E, Sabljic D, Alm B, et al. Driving performance in adults with ADHD: results from a randomized, waiting list controlled trial with atomoxetine. Eur Psychiatry. 2013;28:379-385.

26. Habel LA, Cooper WO, Sox CM, et al. ADHD medications and risk of serious cardiovascular events in young and middle-aged adults. JAMA. 2011;306:2673-2683.

27. Bushe CJ, Bradley A, Pendlebury J. A review of hyperprolactinaemia and severe mental illness: are there implications for clinical biochemistry? Ann Clin Biochem. 2010;47:292-300.

28. Bushe CJ, Slooff CJ, Haddad PM, Karagianis JL. Weight change from 3-year observational data: findings from the worldwide schizophrenia outpatient health outcomes database. J Clin Psychiatry. 2012;73: e749-e755.

29. Chang Z, Lichtenstein P, D’Onofrio BM, Sjölander A, Larsson H. Serious transport accidents in adults with attention-deficit/hyperactivity disorder and the effect of medication. A population-based study. JAMA Psychiatry. 2014;71:319-325.

30. Kessler RC, Adler L, Ames M, et al. The World Health Organization Adult ADHD Self-Report Scale (ASRS): a short screening scale for use in the general population. Psychol Med. 2005;35(2):245-256. 


\section{Supplementary materials}

Read Codes used to define ADHD, and other psychiatric diagnoses and key conditions.

\section{ADHD codes}

\begin{tabular}{lll}
\hline Med code & Read code & Read term \\
\hline 99831 & 9 OI8.00 & ADHD monitoring invitation first letter \\
103937 & 9 OIA.00 & ADHD monitoring invitation third letter \\
9715 & E2E0100 & Attention deficit with hyperactivity \\
6519 & Eu900II & [X]Attention deficit hyperactivity disorder \\
101067 & 6 A61.00 & $\begin{array}{l}\text { Attention deficit hyperactivity disorder } \\
\text { annual review }\end{array}$ \\
6512 & Eu90000 & [X]Disturbance of activity and attention \\
6512 & Eu900008 & [X]Disturbance of activity and attention \\
28543 & ZS9I.00 & Attention deficit disorder \\
24753 & ZS9I.12 & [X]Attention deficit disorder \\
24808 & ZS9I.II & ADD - Attention deficit disorder \\
28543 & ZS9I.00 & Attention deficit disorder \\
\hline
\end{tabular}

Note: ADD was a diagnostic term previously used, which is now more frequently called ADHD.

\section{Psychiatric disorder groups}

Because of the large code files, we have grouped these under general headings.

\begin{tabular}{ll}
\hline Anxiety disorders & Acute stress disorder \\
& Agoraphobia \\
& Anxiety disorder \\
& Generalized anxiety disorder \\
& Panic disorder \\
& Phobic disorder(s) \\
& Social anxiety disorder \\
& Social phobia \\
& Bi-polar (I, II, etc) \\
& Borderline personality disorder \\
& Personality disorder \\
Mood disorders & Hypomanic episode \\
& Impulse control disorder \\
& Manic episode \\
& Adjustment disorder (situational depression) \\
& Depressive disorder \\
& Dysthymia \\
& Major depressive disorder/depression \\
& Major depressive episode \\
Depressive disorders & Depression \\
& Recurrent brief depression \\
& Seasonal affective disorder \\
& Opioid/drug dependence or addiction \\
& Alcohol dependence (alcoholic) \\
& Cannabis dependence \\
& Benzo addiction \\
& Benzo misuse \\
\hline Drug/Alc dependence & \\
& \\
& \\
& \\
&
\end{tabular}

Pragmatic and Observational Research

\section{Publish your work in this journal}

Pragmatic and Observational Research is an international, peer-reviewed, open access journal that publishes data from studies designed to reflect more closely medical interventions in real-world clinical practice compared with classical randomized controlled trials (RCTs). The manuscript management system is completely online and includes a very quick and fair peer-review

\section{Dovepress}

system. Visit http://www.dovepress.com/testimonials.php to read real quotes from published authors. 